\title{
The role of platelet indices as early prognostic factor in ectopic pregnancy cases
}

\section{Ektopik gebelik olgularında erken prognostik faktör olarak trombosit indekslerinin rolü}

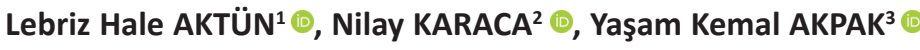

\section{ABSTRACT}

Aim: The aim of the study is to evaluate changes in serum levels of platelet indices such as mean platelet volume (MPV) and platelet distribution width (PDW) in ectopic pregnancy and to investigate whether changes in MPV and PDW have predictive value in ectopic pregnancy.

Methods: Retrospective analysis of 113 women with tubal ectopic pregnancies (26 ruptured and 87 unruptured) and 74 healthy pregnant women in their first trimesters were included in the study. Laboratory data related to hemoglobin, hematocrit, thrombocyte levels, MPV, PDW were analyzed.

Results: In the result, platelet counts were found to be significantly lower in ruptured ectopic pregnancy when compared with unruptured ectopic pregnancies and control groups $(p<0.01)$. MPV levels were especially lower in the ruptured ectopic pregnancy than in the control group, but there was no significant difference between the groups ( $p=0.616)$. PDW levels were higher in the ruptured ectopic pregnancy compared to the control group, but there was no statistically significant difference between the three groups $(p=0.451)$.

Conclusion: The platelet counts tend to be lower in ruptured ectopic pregnancy and indicate platelet consumption in the inflamed area. MPV appears to be lower in ruptured ectopic pregnancy, suggesting potentially higher grade inflammation in the pathology. Our preliminary results suggested that MPV levels may decrease and PDW levels may increase in ruptured ectopic pregnancies. However, further work is needed to define the usefulness of platelet indices in the diagnosis and clinical follow-up of ectopic pregnancies.

Keywords: Ectopic pregnancy, platelet count, mean platelet volume (MPV), platelet distribution width (PDW)
Öz

Amaç: Bu çalışmanın amacı, ektopik gebelikte ortalama trombosit hacmi (MPV) ve trombosit dağılım genişliği (PDW) gibi trombosit indekslerinin serum düzeyindeki değişimleri değerlendirmek ve MPV ve PDW'deki değişikliklerin ektopik gebelikte öngörü değeri taşıyıp taşımadığını araştırmaktır.

Yöntem: Retrospektif olarak 2013 yılı ile 2016 yılları arasında kliniğimize başvuran 113 tubal ektopik gebeliği olan hastalar (26 rüptür ve 87 rüptür olmamış) ve ilk trimesterde 74 sağlıklı gebeliği olan kadınlar çalışmaya alındı. Toplam 187 gebenin hemoglobin, hematokrit, trombosit düzeyi, MPV, PDW ile ilgili laboratuvar verileri analiz edildi.

Bulgular: Trombosit sayıları, rüptüre olmuş ektopik gebelikte, rüptüre olmamış ektopik gebelikler ve kontrol gruplarına göre anlamlı derecede düşük bulundu ( $p<0,01)$. MPV düzeyleri, özellikle rüptüre olmuş ektopik gebelikte kontrol grubuna göre daha düşük bulunmakla birlikte, gruplar arasında anlamlı bir fark bulunama$d_{\imath}(p=0,616)$. PDW seviyeleri ise rüptüre olmuş ektopik gebelikte kontrol grubuna göre daha yüksek bulunmakla birlikte, üç grup arasında istatistiksel olarak önemli bir fark görülmedi $(p=0,451)$.

Sonuç: Sonuç olarak, trombosit sayıları, rüptüre olmuş ektopik gebelikte daha düşük olma eğilimi gösterir ve enflamasyon alanındaki trombosit tüketimini göstermektedir. MPV değerleri ise, patolojide olası yüksek dereceli inflamasyonu düşündüren rüptüre ektopik gebelikte daha düşük gözükmektedir. Ön sonuçlarımız, rüptüre ektopik gebelik olgularında MPV düzeylerinin düşebileceğini aynı zamanda, PDW seviyelerini artırabileceğini göstermektedir. Bununla birlikte, ektopik gebeliğin tanı ve klinik izleminde trombosit indekslerinin yararlılığını tanımlamak için ileri çalışmalara gereksinim vardır.

Anahtar kelimeler: Ektopik gebelik, trombosit, ortalama trombosit volümü (MPV), trombosit dağılım genişliği (PDW)

Received: 23.05 .2018

Accepted: 17.07 .2018

${ }^{1}$ Medipol University, Medical Faculty, Obstetrics and Gynecology, İstanbul, Turkey

${ }^{2}$ Istinye University, Health Application and Research Center, Gaziosmanpaşa Branch, Obstetrics and Gynecology, İstanbul, Turkey

${ }^{3}$ Health Sciences University, Tepecik Training and Research Hospital,Obstetrics and Gynecology, İzmir, Turkey

Yazışma adresi: Nilay Karaca, İstinye University, Health Application and Research Center, Gaziosmanpaşa Branch, Obstetrics and Gynecology, İstanbul, Turkey e-mail: karacanilay@hotmail.com

Yazarların ORCiD bilgileri:

L.H.A. 0000-0001-6141-8265, N.K. 0000-0002-5710-4519, Y.K.A. 0000-0002-1699-8667 


\section{Giriş}

Ektopik gebelik, embriyonun uterin boşluğun dışında implante olmasıdır. Tüm gebeliklerin yaklaşık \%1-2'si ektopik implantasyon ile sonuçlanır ${ }^{1}$. Ektopik gebeliklerin çoğu fallop tüplerinde görülür. Tubal ektopik gebelik için başlıca risk faktörleri, önceki ektopik gebelik, yardımcı üreme teknolojileri ve geçirilmiş tüp cerrahisi olarak sıralanır². Patogenez, fertilize ovumun erken implante olmasına yol açan tubal siliyer disfonksiyon ve fallop tüpünün mikro ortamındaki değişiklikler nedeniyle kusurlu tubal transporta bağlıdır ${ }^{1}$.

Trombositler, pıhtılaşma faktörleri ile birlikte hemostazın sağlanmasında temel işlevleri olan dinamik kan parçacıklarıdır. Bu hücreler, lökosit ve endotel hücreleriyle de etkileşimde bulunduklarından herhangi bir nedenle uyarıldıkları zaman şekil değişikliklerine uğrarlar. Sonuçta, hemostaz için önemli olan yüzey alanlarını ve içlerinde depolanan biyoaktif molekülleri arttırırlar ${ }^{3}$.

Hemostaz ve trombozdaki önemli rollerine ilaveten, trombositler, inflamatuvar sürece, mikrobiyal konakçı savunmasına, yara iyileşmesine, anjiyogenezise ve yeniden modellemeye katkıda bulunmaktadır ${ }^{4}$. Enflamasyona eşlik eden oksidatif stres, trombositleri etkinleştirebilir ve trombositler de lökositlerin intravasküler alandan dokulara hareketine aracılık eder ${ }^{5,6}$. Trombositlerin diğer hücreleri etkileme kabiliyeti, hastalıkların patofizyolojisinde rol oynayabileceği anlamına gelebilir.

Trombosit indeksleri (PI) olarak bilinen ortalama trombosit hacmi (MPV) ve trombosit dağılım genişliği (PDW), otomatik tam kan sayımının bir parçası olarak elde edilen parametreler olup, trombosit aktivasyonunun biyolojik belirtecidirler ${ }^{7,8}$. Fazladan maliyete neden olmaksızın pek çok ortamda kolaylıkla ölçülebilen bu parametreler, hastalıkların ciddiyetini değerlendirmek için kullanılabilir. Trombosit indekslerinin hepsinin aynı anda ölçülmesi, bu indekslerde değişikliğe neden olan potansiyel etiyolojinin tanısı ve prognozu konusunda bilgi verebilir. Yakın zamanda yapılan çalışmalar, trombosit indekslerinin tromboz, anjiogenez, inflamasyon ve bağışıklık işlevlerindeki rolünü vurgulamıştır ${ }^{9}$. Dolayısıyla; trombosit indekslerinin, romatoid artrit, ankilozan spondilit, ülseratif kolit ve ateroskleroz gibi bazı inflamatuvar hastalıklarda tanısal ve prognostik değeri olabileceği ileri sürülmüştür ${ }^{10-12}$. Aynı şekilde, ektopik gebelikte de, trombosit indeksleri gibi bazı inflamatuvar parametreler, hem implantasyon sahasında hem de sistemik dolaşımda değişikliğe uğramaktadır ${ }^{1}$.

Bu çalışma, ektopik gebelik olgularında, MPV ve PDW gibi trombosit indekslerinde meydana gelen değişiklikleri incelemeyi ve bu değişikliklerin ektopik gebelik prognozunda öngörü değeri taşıyıp taşımadığını araştırmayı amaçlamıştır.

\section{GEREÇ ve YÖNTEM}

Etik Kurul onayı alındıktan sonra, Ocak 2013-Aralık 2016 yılları arasında çalışma merkezine başvuran ve tubal ektopik gebelik tanısı konulan 113 olguya (rüptüre olmuş 26 olgu ve rüptüre olmamış 87 olgu) ve ilk trimesterde sağlıklı gebeliği olan 74 kadına ait verilerin retrospektif olarak karşılaştırılmasına dayaIı bir vaka-kontrol çalışması planlandı. Normal dışı jinekolojik öyküsü olmayan, ultrasonografi ile gebelik yaşı onaylatılan ve son menstrüel periyoda göre 12. gebelik haftasına kadar takip edilerek gebeliğinin normal devam ettiği bilinen kadınlar, kontrol grubunu oluşturdu. Bilinen sistemik metabolik ve kronik inflamatuvar hastalıkları olan gebeler (sistemik lupus eritematozis, romatoid artrit, vaskülit, böbrek ve karaciğer yetmezlikleri, hemoglobinopati, diyabet, hipertansif bozukluklar, daha önce myokard enfarktüsü ve tromboz öyküsü gibi) çalışma dışı bırakıldı. Toplam 187 gebenin demografik özellikleri ve laboratuvar bulguları incelendi.

Venöz kan örnekleri alındıktan sonra 2 ml'lik K3 EDTA'lı tüplere boşaltılarak bekletilmeden incelendi. Tam kan sayımı, otomatik hematoloji analiz cihazında yapıldı (XT2000i; Symex, Osaka, Japonya). 


\section{İstatistiksel Analiz}

Veriler, Sosyal Bilimler için İstatistiksel Paket programı (sürüm 15,0, SPSS IBM, Armonk, NY, USA) kullanılarak analiz edildi. Sürekli değişkenler, ortalamaıstandart sapma olarak belirtildi. İkili grup karşılaştırmaları için Student t testi, çoklu grup karşılaştırmaları için ise ANOVA testi ve sonrasında Tukey's HSD testinden yararlanıldı. Çift tarafı $p<0,05$, istatistiksel olarak önemli kabul edildi.

\section{BULGULAR}

Tablo 1'de, ektopik gebelik olgularının ve sağlıklı gebe kadınların demografik özellikleri ve laboratuvar değerleri karşılaştırılmıştır. Ektopik gebelik ve kontrol grupları arasında yaş, hemoglobin, hematokrit, platelet sayımı, PDW ve MPV değerleri bakımından

Tablo 1. Ektopik gebelik ve kontrol gruplarının demografik özellikleri ve laboratuvar değerleri.

\begin{tabular}{lllc}
\hline & $\begin{array}{l}\text { Ektopik gebelik } \\
(\mathbf{n = 1 1 3 )}\end{array}$ & $\begin{array}{l}\text { Kontrol } \\
(\mathbf{n = 7 4 )}\end{array}$ & $\mathbf{p}$ \\
\hline Yaş (yl) & $28,13 \pm 2,64$ & $27,64 \pm 2,9$ & 0,345 \\
Hemoglobin $(\mathrm{gr} / \mathrm{dl})$ & $12,15 \pm 0,26$ & $12,36 \pm 0,43$ & 0,740 \\
Hematokrit $(\%)$ & $33,65 \pm 2,05$ & $34,45 \pm 1,65$ & 0,564 \\
Platelet $\left(\times 10^{3} / \mathrm{mm}^{3}\right)$ & $245,12 \pm 61,73$ & $251,32 \pm 37,41$ & 0,432 \\
PDW (\%) & $16,65 \pm 3,43$ & $16,43 \pm 3,31$ & 0,231 \\
MPV (fl) & $8,65 \pm 1,09$ & $8,73 \pm 0,48$ & 0,330 \\
& & & \\
\hline
\end{tabular}

$P D W=$ trombosit yayılım genişliği, MPV=ortalama trombosit volümü

Tablo 2. Rüptüre olmuş ve olmamış ektopik gebelik olgularının ve kontrol grubunun demografik özellikleri ve laboratuvar değerleri.

\begin{tabular}{|c|c|c|c|c|}
\hline & $\begin{array}{l}\text { Rüptüre } \\
\text { olmuş } \\
\text { ektopik } \\
\text { gebelik } \\
(n=26)\end{array}$ & $\begin{array}{l}\text { Rüptüre } \\
\text { olmamış } \\
\text { ektopik } \\
\text { gebelik } \\
\text { (n=87) }\end{array}$ & $\begin{array}{l}\text { Kontrol } \\
(n=74)\end{array}$ & p \\
\hline Yaş (yıl) & $27,18 \pm 1,45$ & $26,23 \pm 2,1$ & $27,14 \pm 1,3$ & 0,053 \\
\hline Hemoglobin (gr/dl) & $11,72 \pm 0,58$ & $11,92 \pm 0,8$ & $12,16 \pm 1,2$ & 0,426 \\
\hline Hematokrit (\%) & $33,45 \pm 2,05$ & $33,12 \pm 1,01$ & $34,45 \pm 1,65$ & 0,564 \\
\hline Platelet $\left(\times 10^{3} / \mathrm{mm}^{3}\right)$ & $205,12 \pm 21,73$ & $242,01 \pm 15,1$ & $251,32 \pm 37,41$ & $0,005^{*}$ \\
\hline PDW (\%) & $16,27 \pm 2,82$ & $16,35 \pm 3,43$ & $16,43 \pm 3,31$ & 0,431 \\
\hline MPV (fl) & $8,57 \pm 0,76$ & $8,55 \pm 1,09$ & $8,73 \pm 0,48$ & 0,630 \\
\hline
\end{tabular}

$P D W=$ trombosit yayılım genişliği, $M P V=$ ortalama trombosit volümü, ${ }^{*} p<0,05$, istatistiksel olarak anlamlı kabul edildi. anlamlı bir farklılık bulunamadı (sırasıyla $p=0,345$, $p=0,740, p=0,564, p=0,432, p=0,231$ ve $p=0,330)$.

Tablo 2'de rüptüre olmuş ektopik gebelik olgularının, rüptüre olmamış ektopik gebelik olgularının ve sağlıklı gebe kadınların demografik özellikleri ve laboratuvar değerleri karşılaştırılmıştır. Rüptüre olmuş ektopik gebelik olguları, rüptüre olmamış ektopik gebelik olguları ve sağlıklı gebe kadınlar; yaş, hemoglobin, hematokrit, PDW ve MPV değerleri bakımından istatistiksel olarak benzerdi (sırasıyla $p=0,053$, $p=0,426, p=0,564, p=0,431$ ve $p=0,630)$. Rüptüre ektopik gebelik olgularının trombosit seviyeleri, rüptüre olmamış ektopik gebelik olgularının ve kontrol grubunun trombosit seviyelerinden anlamlı olarak düşüktü $(p<0,01)$.

\section{TARTIŞMA}

Ektopik gebelik, maternal mortalite açısından hala daha yüksek risk taşıyan bir hastalıktır ${ }^{9}$. Özellikle tubal ektopik gebelik olguları, tubanın anatomik yapısı nedeniyle önem taşımaktadır. Tubal ektopik gebeliğin fizyopatolojisinde, cerrahi ve enfeksiyon gibi çeşitli nedenler dolayısıyla tubanın oosit transportundaki işlevinin bozulması ve tuba lümenindeki mikroçevrenin değişmesi söz konusudur ${ }^{1}$. Anne ölümlerini önlemede ektopik gebeliklerin erken tanısı oldukça önemlidir. Bu nedenle, erken tanıya yönelik pek çok çalışma planlanmıştır ${ }^{2,13-15}$.

Ektopik gebelik olgularının \%30'u asemptomatiktir ancak bazıları hemodinamik şok tablosunda başvurabilir ${ }^{6,17}$. Tanı, genel olarak seri beta HCG ölçümleri ve ultrasonografi yardımıyla konulmaktadır². Gün aşırı yapılan seri beta HCG ölçümlerinde en az \%66 değerindeki artış, genellikle sağlıklı bir gebeliğin göstergesi olarak kabul edilse de özellikle 1500 mlü/ $\mathrm{ml}$ altındaki değerlerde ektopik ve erken gebeliklerin ayırıcı tanısı zor olabilir ${ }^{18}$. Bu nedenle, ilk gebelik muayenesinde rutin olarak bakılan biyokimyasal testlerin ayırıcı tanıda kullanılması anlam taşımaktadır. Bu testlerden en önemlisi, ilk muayenede bakılan tam kan sayımı parametreleridir. 
Tam kan sayımı yapılarak değerlendirilebilen trombosit sayısı ve trombosit indeksleri, ektopik gebeliğin oluşturduğu inflamatuvar süreç hakkında bilgi verebilir. Bunun nedeni, daha önce yapılan çalışmalarda, inflamasyon sırasında MPV değerlerinin arttığının bildirilmesidir. Gasparyan ve ark.'nın ${ }^{19} 168$ çalışmayı inceledikleri meta-analizde, psöriazis, ailevi Akdeniz ateşi ve ateroskleroz gibi daha az sistemik inflamasyona yol açan hastalıklarda MPV değerlerinin daha düşük seyrettiği ve lupus ile romatoid artrit gibi daha fazla sistemik inflamasyona neden olan hastalıklarda MPV değerlerinin daha yüksek olduğu sonucuna varılmıştır.

Ülkümen ve ark. ${ }^{13}, 153$ ektopik gebelik olgusunu incelemiş ve özellikle rüptüre olmuş ektopik gebelik olgularında MPV değerlerinin düştüğünü, PDW değerlerinin yükseldiğini ancak trombosit sayılarının azaldığını belirlemiştir. Öte yandan, Turgut ve ark. ${ }^{20}$, 138 ektopik gebelik olgusunu değerlendirmiş ve MPV değerlerinin yükseldiğini bildirmiştir. Bu çalışmada ise, özellikle rüptüre olmuş ektopik gebelik olgularında yalnızca trombosit sayımının azaldığı belirlenmiştir. Yine, özellikle rüptüre ektopik gebelik olgularında MPV değerlerinin oranla azaldığı ve PDW değerlerinin oranla arttığı ancak bu değişikliklerin istatistiksel olarak anlamlı olmadığı belirlenmiştir. Bunun nedeni, ektopik gebeliğin daha az sistemik inflamasyona yol açması olabilir.

Trombosit aktivasyonu ile MPV ve PDW değerleri arasındaki ilişkiyi açıklamak bazı faktörlerden dolayı zor olabilir ve bu zorluk nedeniyle, söz konusu ilişkiyi inceleyen çalışmalarda farklı sonuçlar elde edilebilir. Örneğin, kan alındıktan sonraki inceleme süresinin uzaması ile MPV değerleri artabilir ve PDW değerleri azalabilir ${ }^{21}$. Aynı şekilde kan örneğinin olduğu tüpteki anti-koagülan ajanın farklı olması da bu değerleri etkileyebilir ${ }^{19,22,23}$. Üstelik gebelik haftasına bağlı olarak oluşan dilüsyonel trombositopeniyi düzeltmek amacıyla MPV ve PDW seviyeleri artabilir ${ }^{22}$. Ayrıca, hipertansiyon, hiperlipidemi ve sigara alışkanlığı gibi etkenler de trombosit aktivasyonunu değiştirebilir ${ }^{24}$.

Tüm bu nedenlerden dolayı, çalışma kohortları ara- sındaki farklılıkların ayrıntılı olarak incelenmesi, trombosit sayısı ve fonksiyonlarının ektopik gebelik olgularında nasıl değiştiğinin araştırılmasında önemli olacaktır. Bu çalışmada, rüptüre ektopik gebelik olgularındaki trombosit sayısının anlamlı olarak azaldığı belirlenmiştir ve bu bulgu, inflamasyon alanındaki trombosit tüketiminin fazla olması ya da oluşan hemorajik tablo ile ilişkili olabilir. Rüptüre ektopik gebelik olgularında, istatistiksel olarak anlamlı olmasa da, MPV değerlerinin göreceli olarak daha düşük ve PDW değerlerinin göreceli olarak daha yüksek olması da, inflamasyona bağıı trombosit tüketimini düşündürmektedir. Ancak, olgu sayısının az olması ve seri tam kan sayımı değerleriyle karşılaştırmaların yapılmamış olması, ulaşılan bulguların gücünü kısıtlamaktadır. Bu çalışma, rüptüre ektopik gebelik olgularında, MPV düzeylerinin düşebileceğini ve PDW seviyelerinin yükselebileceğini göstermektedir.

Maternal mortalitenin en önemli nedenlerinden biri olan ektopik gebelik durumunda, erken tanının ve prognozun belirlenmesi için seri beta HCG ölçümlerinin ve ultrasonografi incelemesinin yanı sıra tam kan sayımında yer alan trombosit indekslerinden yararlanılabilir. Ektopik gebelik olgularının tanısında ve klinik takibinde trombosit indekslerinin kullanılıp kullanılamayacağını anlamak amacıyla geniş ölçekli ve iyi düzenlenmiş çalışmalara gereksinim duyulmaktadır.

\section{KAYNAKLAR}

1. Shaw JLV, Dey SK, Critchley HOD, Horn AW. Current knowledge of the aetiology of human tubal ectopic pregnancy. Human Reproduction Update. 2010;16(4):432-44. https://doi.org/10.1093/humupd/dmp057

2. Varma R, Gupta J. Tubal ectopic pregnancy. Clin Evid. 2009;04:1406.

3. Lopez E, Bermejo N, Berna-Erro A, Alonso N, Salido GM, Redondo $\mathrm{PC}$, et al. Relationship between calcium mobilization and platelet $\alpha$ - and $\delta$-granule secretion. A role for TRPC 6 in thrombin-evoked $\delta$-granule exocytosis. Arch Biochem Biophys. 2015;585:75-81. https://doi.org/10.1016/j.abb.2015.09.012

4. Golebiewska EM, Poole AW. Platelet secretion: From haemostasis to wound healing and beyond. Blood Rev. 2015;29:15362.

https://doi.org/10.1016/j.blre.2014.10.003

5. Monteiro PF, Morganti RP, Delbin MA, Calixto MC, LopesPires ME, Marcondes $\mathrm{S}$, et al. Platelet hyperaggregability in high-fat fed rats: A role for intraplatelet reactive-oxygen species production. Cardiovasc Diabetol. 2012;11:5. 
https://doi.org/10.1186/1475-2840-11-5

6. Karimi P, Rashtchizadeh N. Oxidative versus thrombotic stimulation of platelets differentially activates signalling pathways. J Cardiovasc Thorac Res. 2013;5:61-5.

7. Larsen SB, Grove EL, Hvas AM, Kristensen SD. Platelet turnover in stable coronary artery disease-influence of thrombopoietin and low-grade inflammation. PLoS One. 2014;9:e85566. https://doi.org/10.1371/journal.pone.0085566

8. Osselaer JC, Jamart J, Scheiff JM. Platelet distribution width for differential diagnosis of thrombocytosis. Clin Chem. 1997;43:1072-6.

9. Wagner DD, Burger PC. Platelets in inflammation and thrombosis. Arterioscler Thromb Vasc Biol. 2003;23:2131-7. https://doi.org/10.1161/01.ATV.0000095974.95122.EC

10. Margetic S. Inflammation and haemostasis. Biochem Med (Zagreb). 2012;22:49-62. https://doi.org/10.11613/BM.2012.006

11. Thachil J. Platelets in inflammatory disorders: a pathophysiological and clinical perspective. Semin Thromb Hemost. 2015;41:572-81. https://doi.org/10.1055/s-0035-1556589

12. Takeyama H, Mizushima T, lijima H, Shinichiro S, Uemura M, Nishimura J, et al. Platelet activation markers are associated with Crohn's disease activity in patients with low C-reactive protein. Dig Dis Sci. 2015;60:3418-23. https://doi.org/10.1007/s10620-015-3745-2

13. Artunc Ulkumen B, Pala HG, Calik E, Oruc Koltan S. Can mean platelet volume and platelet distrubition width be possible markers for ectopic pregnancy and tubal rupture? (MPV and PDW in ectopic pregnancy). Pak J Med Sci. 2014;30(2):352-5.

14. Condous G, Okaro E, Khalid A, et al. The accuracy of transvaginal ultrasonography for the diagnosis of ectopic pregnancy prior to surgery. Hum Reprod. 2005;20:1404-9. https://doi.org/10.1093/humrep/deh770

15. Banerjee S, Aslam N, Woelfer B, et al. Expectant management of early pregnancies of unknown location: a prospective evaluation of methods to predict spontaneous resolution of pregnancy. BJOG. 2001;108:158-63.

https://doi.org/10.1111/j.1471-0528.2001.00031.x

16. Tay JI, Moore J, Walker JJ. Ectopic pregnancy. BMJ. 2000;320:916-9.

https://doi.org/10.1136/bmj.320.7239.916

17. Cartwright J, Duncan WC, Critchley HOD, Horne AW. Serum biomarkers of tubal ectopic pregnancy: current candidates and future possibilities. Reproduction. 2009;138(1):9-22. https://doi.org/10.1530/REP-09-0060

18. Cabar FR, Fettback PB, Pereira P, Zugaib M. Serum markers in the diagnosis of tubal pregnancy. Clinics. 2008;63:701-8. https://doi.org/10.1590/S1807-59322008000500021

19. Gasparyen AY, Ayvazyen L, Mikhalidis D. MPV: a link between thrombosis and inflammation? Current Pharmaceutical Design. 2011;17(1):47-58. https://doi.org/10.2174/138161211795049804

20. Turgut A, Sak ME, Ozler A. Alterations of peripheral blood cells in tubal ecto Ginekol Pol. 2013;84:193-6. https://doi.org/10.17772/gp/1562

21. Vagdatli E, Gounari E, Lazaridou E. Platelet distribution width: a simple, practical and specific marker of activation of coagulation. Hippokratia. 2010;14:28-32.

22. Dundar O, Yoruk P, Tutuncu L. Longitudinal study of platelet size changes in gestation and predictive power of elevated MPV in development of preeclampsia. Prenat Diag. 2008;28:1052-6. https://doi.org/10.1002/pd.2126

23. Beyan C, Kaptan K, Ifran A. Platelet count, mean platelet volume, platelet distribution width, and plateletcrit do not correlate with optical platelet aggegation responses in healthy volunteers. J Thromb Thrombolysis. 2006;22(3):161-4. https://doi.org/10.1007/s11239-006-9014-7

24. Ihara A, Kawamoto T, Matsumoto K, Shouno S. Relationship between hemostatic factors and the platelet index in patients with ischemic heart disease. Pathophysio Haemost Thromb. 2006;35(5):388-91. https://doi.org/10.1159/000097694 